Hammer, N. and R. Plugor (forthcoming) Near-Sourcing UK Apparel: Value Chain Restructuring, Productivity, and the Informal Economy, Industrial Relations Journal

\title{
Near-Sourcing UK Apparel: Value Chain Restructuring, Productivity, and the Informal Economy
}

\author{
Abstract \\ Fast fashion's emphasis on quick response production and supply chain management is at the basis of \\ renewed growth in UK apparel manufacturing. This article shows how increasing pressure from lead \\ firms has resulted in manufacturers maintaining profit levels, mainly through informal subcontracting \\ and informal employment, as opposed to increasing productivity.
}


The precipitous decline of UK apparel manufacturing over the last four decades largely confirmed expectations about competitive advantage in a free trade environment. A labour intensive industry, UK apparel manufacturing was suffering from a long-recognised productivity deficit compared to its European competitors (e.g. Lane and Probert 2009, 45; Walsh 1991) and was poorly placed to meet the challenges that emerged in the 1970s from South-East Asia; challenges that have grown since through the emergence of new sourcing locations and the phasing out of the multi-fibre agreement (MFA) in 2004. The decline started in the 1970s and accelerated in the 1990s. Over the period 1996-2014, real turnover ${ }^{1}$ suffered a 52 percent decline as the number of jobs fell by 82 percent ${ }^{2}$. However, the recent counterintuitive reversal in the industry's fortunes throws up a range of questions as to the underlying competitiveness of apparel manufacturing in the UK: while UK wide figures mask regional divergence, regional statistics point to considerable growth in London and the East Midlands of 75 and 52 percent (2008-13), respectively, with the East Midlands as the UK's largest sourcing hub accounting for almost a third of the industry's real turnover in 2013.

This phenomenon has been examined under the rubric of 'reshoring' manufacturing production which, according to government sources, is based on four "key factors that have prompted companies to move production [back to the UK, NH\&RP]: to improve quality; to shorten lead times; to improve delivery performance and strengthen the supply chain; [and to] reduce labour costs." (Prime Minister's Office 2014) The Prime Minister himself has spoken of the seamstresses in the Midlands and the good news of garment production being brought back onshore (HC Deb 18 March 2015). Implicit in this list of factors is a theory emphasising the location and externalisation advantages of reshoring, a perspective that is

\footnotetext{
${ }^{1}$ Unless indicated otherwise data for the UK are taken from the Annual Business Survey (ABS), data for the regional level are from the regional results of the ABS. Note that ABS data from 2008 onwards shift from SIC 2003 to SIC 2007 classification. For apparel manufacturing this means that hosiery and knitted garments are included in 'wearing apparel' whereas the manufacture of articles of fur is excluded.

${ }^{2}$ These employment data are from the ONS table 'JOBSO3 Employee Jobs by Industry (not seasonally adjusted)'.
} 
not well suited to grasp key conditions of reshoring, not least because the mutually supportive character of the four key factors cannot be taken for granted.

This article aims to explain the reshoring of apparel manufacturing to the UK. There is an apparent tension between the growth of the UK apparel industry and the trends that highlight low producer prices, low labour productivity, and relatively high real wage growth, thereby questioning the actual basis of the industry's growth. The argument focuses on the role of work relations in sustaining these contradictory developments. In doing so it explains the factors behind reshoring in this industry and also contributes to new debates highlighting the relationships between value chain governance, work and employment (see Newsome et al 2015).

It is argued that the societal organisational context of productivity needs to be analysed in conjuncture with developments at the level of value chains. As will be shown, the emergence of a form of value chain and production governance that is often referred to as fast fashion had a crucial impact on forms of competition and coordination - both, horizontal and vertical - which circumscribe the scope of workplace management. This framework helps to explain how the functional division of labour within (reshored) fast fashion produces, and relies on, tiers of manufacturers and segmented vulnerable workers with adverse implications for productivity, thereby entrenching a business model that favours a low road to high growth.

The article is structured as follows. The first section considers relevant theoretical approaches before positioning social relations at work - and productivity - within the context of global value chains (GVCs). Then follows an overview of the methods employed to research supply chains, work, and employment in the informal economy. The next sections present evidence of reshoring in UK apparel manufacturing before analysing qualitative case study data that is able to resolve the apparent tensions in official statistics. Finally, the conclusion re-emphasises the role of social relations for the analysis of reshoring and draws out theoretical and policy implications. 


\section{Global Value Chain Restructuring and Productivity}

As exciting as reshoring might be from academic and political perspectives, as cautious have been assessments of the empirical evidence (e.g. Bailey and DePropris 2014). Accepting the analytical difference between changes in the boundaries of the firm and changes across geographical borders, reshoring tends to be defined narrowly, relating to the return of offshored owned units or functions. The international business literature, in particular, has conceptualised this very neatly: its emphasis on internalisation decisions on the one hand, on location decisions on the other, has led to a differentiation of four different types of movements (see Gray et al 2013). The changes in UK apparel manufacturing that are the focus of this article would be classed as a form of 'outsourced reshoring', that is, a movement of outsourced offshore to outsourced onshore functions. This term, however, has a strong focus on the ownership and geographical relationships between business units and is not well placed to capture the power dynamics in the functional division of labour. Instead, this paper will use the term near-sourcing which gives a better sense of its function within broader and constantly contested sourcing portfolios of lead firms, a contestation along and about the key parameters of value chain governance.

Regional clusters in the textile and apparel industry have featured prominently in the literature on industrial districts. Here, economies of scale have been replaced by economies of scope which are reinforced by efficiencies that derive from collaboration in dense, proximate, inter-firm networks. Production relies on advantages of quality and speed in order to serve niche markets. However, while these factors certainly play a role in the case of the East Midlands (although the latter are largely focused on fashion basics as well as trial and repeat orders rather than high-end niche markets), an important drawback of the literature on industrial districts and flexible specialisation is that it treats GVC governance as external (e.g. Lan 2015; Doeringer and Crean 2006). In contrast, the case and the 
argument developed below emphasise the intricate interrelations between GVC governance and lead firms' supply chain practices, on the one hand, and the forms of collaboration amongst regional manufacturers, on the other, whereby the latter are both a product and a condition of the former. Global value chain analysis is concerned with the functional division of labour across territories. Research on GVCs equally had an early concern with apparel and has, across the theoretical range of GVC and global production network accounts (Bair 2009), made crucial contributions to the analysis of the changing divisions of labour in apparel production. Aiming to widen the GVC approach's grasp of different forms of network governance Gereffi et al (2005) developed a typology of GVC governance that built on key elements of transaction cost theory. A central problem with this conceptualisation, however, is that a characterisation of value chain governance in terms of transaction costs privileges a firm-to-firm node (Gibbon et al 2008) at the expense of the governance of a more extended value chain. Furthermore, it focuses on the functional division of labour within that node, rather than considering the vertical division of labour (and competition) in the context of the horizontal division of labour and competition. As this research will demonstrate, the captivity of manufacturers is not solely a function of the scope to codify information for transactions and the respective capabilities of manufacturers. Critical perspectives from political economy and labour market segmentation (e.g. Grimshaw and Rubery 2005; Fine 1998), for example, would argue that the functional division of labour cannot be thought independently of forms of product market competition, labour market regulation, as well as management-labour relations at work.

The GVC approach has however served as a basis to differentiate developments in apparel GVCs further. Analysing the evolution of fast fashion, for example, Taplin (2014) has integrated accounts of volatile and differentiated consumer demand with supply-side chain rationalisation. The emergence of lean retailing has institutionalised quick response strategies in the supply chain, with a further differentiation between cost-based strategies, on the one hand, and cost- and speed-to-market-based strategies on the 
other. Particularly the latter allow not only to push but also to pull a constant stream of novel fashion basic products through the chain (thereby institutionalising swift changes in fashion lines, tight links and quick responses to trends in popular culture). Taplin (2014, 251 referring to Riddle et al 1999, 134) argues that the underlying logic of supply chain rationalisation through quick response strategies "became a competitive necessity for manufacturers rather than a source of competitive advantage since the majority of benefits (sales increases, stock reduction and forecasting error) accrued to retailers." The approaches discussed above analyse a range of factors that drive competitiveness and productivity in different ways: the focus, however, is mostly on dynamics in inter-firm networks (even if the latter are conceived as value chains) or firm strategies in order to gain access to those networks. Following new debates to put labour back into value chains (Newsome et al 2015), however, a space opens up to analyse productivity not only as a function of inter-firm relations but of a business and management model particular forms of value chain governance give rise to. Such attention to the role of workplace social dynamics in GVCs (Hammer and Riisgaard 2015) chimes with the sociological approach in debates on Britain's productivity record, that is, its emphasis on effort, the need to extract labour from labour power and, in consequence, the effect of work organisation, management approaches, and industrial relations (e.g. Nolan and O'Donnell 1995)

What has changed compared to earlier debates is the organisational context of productivity. The unit of analysis - the firm, establishment, or workplace - often has disintegrated as particular production functions have been outsourced and/or offshored, making it very implausible in the contemporary industrial relations context to blame trade unions' restrictive practices for the productivity deficit. The separated units have been placed in different horizontal and vertical competitive contexts that impinge on the ways production and the workforce are managed. Different forms of GVC governance shape access to develop a range of firm capabilities and shape the context in which societally embedded forms of production and the extraction of labour from labour power take place. A key question, then, is about 
the strategic selectivity of concurrent value chain and societal factors for the dominant business model, and to what extent this can explain recent phenomena of near-sourcing.

Broadly, two possible routes towards near-sourcing can be contrasted: upgrading in the functional division of labour as opposed to a shift into the informal economy. Drawing on value chain analysis, the first route is driven by advanced productivity which, in conjunction with quality and speed-to-market advantages, is able to establish a (fast fashion) market that does not compete directly with more standardised volume production. In this case, aspects of flexible specialisation may play a role; suppliers and manufacturers might be able to develop strategic capabilities to feed into the emerging fast fashion market, and gain a more independent position (of full package production) as GVC theory would have it. The second route sees suppliers and manufacturers locked into more price competition than can be absorbed by design quality, quality production, and responsive speed-to-market capabilities. Manufacturers' attempts to upgrade capabilities and to increase productivity will inevitably be countered by adverse value chain practices and product market competition. In order to stay in the market, manufacturers might try to reduce their costs below legal minima and to operate on the blurred boundary of the informal economy.

\section{Researching Supply Chains in the Informal Economy}

The emergence of the fast fashion production model (Taplin 2014) gave an important impetus to nearsourcing in the UK as it has not only re-shaped consumer markets but also established new requirements for suppliers and manufacturers. However, changing forms of value chain governance between lead firms, suppliers, manufacturers - as well as labour, NGOs and public authorities - also pose challenges for research, particularly as product and labour markets shifted to the blurred boundary of the formal and informal economies. Research in employment relations has often focused on interfirm nodes in tracing the effect of different inter-firm relations on work and employment. A value chain 
analysis that integrates embedded forms of production allows going beyond such narrow boundaries as it considers the role of (product and process) standards that govern relationships along the entire value chain. In this respect, it can help in the analysis of work and employment in a context-sensitive way (Edwards 2005), paying attention to changes in the broader division of labour in the context of locally embedded processes.

The aims of the underlying research, a project carried out for the Ethical Trading Initiative (ETI; see Hammer et al 2015), underlined the need for a mixed methods approach (Morse 2010) in order to be sensitive to the social and economic dynamics at different stages of the fast fashion value chain in the UK. As growth in apparel manufacturing was renewed, concerns grew within the industry that established forms of coordination, the governance of ethical apparel manufacturing, and supply chain transparency were undermined. Lead firms tend not to have any commercial relationship with the manufacturer except that of quality control and social auditing as they normally place their orders with suppliers who act as intermediaries with specific design, logistics and production coordination capabilities. However, further subcontracting beyond declared manufacturers bypasses lead firm audits (however weak and problematic in themselves) and is likely to undermine fundamental work and employment standards.

The research was therefore based on a multi-faceted methodology that investigated actors at different stages of the value chain (from lead firm practices to informal employment), through different methods, and through socially and ethnically embedded researchers where possible. Four methodological strategies were pursued in this respect. First, based on confidential information from ten lead firms and social auditors, as well as publicly available information (including a freedom of information request), a database was established to map relationships within the supply chain as well as data on major violations of work and employment standards. Second, 30 semi-structured interviews were conducted with a wide range of industry stakeholders such as workers, ethical trade managers and buyers in lead 
firms, suppliers, first and second tier manufacturers, industry associations, trade unions, public agencies, advice/welfare/community organisations, NGOs, and the broader auditing community. Third, with the support of ETI and the UK Fashion and Textile Association a forum was held with suppliers, first and second tier manufacturers (attended by around 30 representatives from Leicester and the East Midlands) that offered an opportunity to discuss key issues without lead firms present. Finally, a smallscale survey on working conditions developed by the research team was carried out by a community organisation, the Pakistan Youth and Community Association, that gathered data from 30 worker respondents.

These methods aimed to capture data from different stages of the value chain from different perspectives (e.g. asking lead firms about factories they source from and workers which branded goods they produce), and to gather data in a socially and ethically appropriate environment. Most importantly, this concerned women workers of SE Asian background whose interviewers had a similar ethnic background; also, the majority of interviews was conducted by a female researcher. Furthermore, it was crucial to create a safe space for all respondents in order to allow openness about evidence or even their own voluntary or forced complicity in unauthorised subcontracting and informal employment. As all relationships within the supply chain are contested, either between actors in a different functional position in the chain, or between workers and employers, these different types of data were triangulated to enable counter-factual analyses and evaluations.

\section{Restructuring, Near-Sourcing and Productivity}

Apparel manufacturing in the UK has shrunk considerably as production was off-shored to the Far East from the 1970s onwards (Lane and Probert 2009; Walsh 1991). In the period 1996-2014 turnover measured in real terms has declined by 52 percent, accompanied by a 64 percent drop in the real approximate Gross Value Added (aGVA). In the same time the number of enterprises has fallen by 59 
percent to 3,415 and the contribution of apparel manufacturing to total manufacturing decreased from 2 percent to 0.6 percent. Employment fell even more drastically by 82 percent (disproportionally affecting female workers with an 87 percent drop) and stood at 34,000 employees in 2014. As fundamental as the extent of the decline, though, was the structural transformation within apparel manufacturing (see Table 1). Gibbon (2001; see also Lane and Probert 2009) has pointed to the emergence of new types of lead firms in the 1990s, and this assessment has not lost any validity in the 2000s. Few of the top 10 clothing firms of the current decade were in the same bracket in the 1990s or had barely been founded by then. More importantly, what have come through in this respect were not only new brand names but also new business models. For example, there is much more variety to the high-street, own brand, fashion retailers in the contemporary (real or virtual) high-street. Initially, the former established retailers were put under pressure by discount retailers and the last years have seen general retailers developing clothing brands, general retailers building an online presence, and even the emergence of online-only brands and retailers.

The rise of fast fashion has, against the backdrop of a longer historical process of off-shoring, led to regional divergence. While the production of wearing apparel continued on a slow decline in other regions, real turnover and aGVA in the East Midlands rose significantly by 52 and 39 percent (2008-13), respectively, which was only exceeded by 75 and 78 percent rises in London. Together, the East Midlands and London accounted for just over half of the UK's apparel industry in 2013. Importantly, the industry's firm structure has also changed drastically, continuing a historical trend: not only has the number of firms declined by 61 percent between 1995-2014, their average size has more than halved from 22.2 to 10 employees. Still, data from 2013 show that the firm structure in the East Midlands is much larger than the UK average: 85 percent of apparel manufacturers in the region employ fewer than 20 people, 13 percent fall into the $20-99$ employees bracket, and $2 \%$ employ more than 100 . Table 1 offers clear evidence of the boom in apparel manufacturing after 2008 and also points to the 
containment of employment costs as one possible factor (the increase in employment costs remains considerably below that of turnover and aGVA and is in line with the UK overall). In this restructuring process, the East Midlands strengthened their position as the largest apparel manufacturing hub in the UK, growing from around 17 to 30 percent of the UK's apparel turnover and aGVA (1998-2013).

[Table 1 about here]

Available statistical data allow further analysis of the near-sourcing phenomenon in wearing apparel. Figure 1 considers the competitive position of the industry from the perspective of producer prices (also referred to as factory gate prices) and consumer prices. Most remarkable is that the consumer price index (CPI) for clothing exhibits significantly negative growth rates until 2010, amounting to a cumulative fall of 51 percent between 1996-2014, at the same time as overall inflation rose by 45 percent. This contrasts with factory gate prices for wearing apparel that have grown considerably slower than the producer price index (PPI) for manufacturing as a whole, the former rising by 17 percent compared to the latter's 41 percent. While apparel manufacturers, on the face of this evidence, have substantially improved their competitive position, at least in relation to manufacturing as a whole, it is worth exploring the main drivers behind this development. The discussion therefore turns to the role of structural change, technology, input costs as well as labour-management relations across the two phases identified above.

[Figure 1 about here]

First, a PPI higher than the CPI might point to structural change in UK wearing apparel towards more high-end clothing which raises factory-gate prices overall. However, while this might be the case in some 
niche markets, this is by far insufficient in explaining the extent of the gap between PPI and CPI as well as its long-term trend. Second, investment in technology could have raised productivity and kept the PPI for wearing apparel below that for manufacturing. This argument, though seems implausible as capital expenditure in wearing apparel fell faster than in manufacturing (see Table 2 below) precisely in the period 1999-2007 when the former's PPI growth was significantly below the latter's. Third, PPI growth in wearing apparel could have stayed relatively low due to decreasing input costs. This was certainly true for material inputs but not for real pay per hour which increased at a higher rate than in manufacturing across both periods. Growth rates of real hourly pay of around 5-6 percent would certainly weigh in a labour-intensive industry as apparel manufacturing. Nonetheless, pay should not be considered outside the context of productivity developments which leads to a fourth point about labour-management relations.

Labour productivity rose considerably faster than real hourly pay during 1999-2007 but dropped to a negative growth rate $2008-2014$, more than 5 percent below the growth of hourly pay (Table 2 ). As earlier debates on the UK's productivity deficit attributed the blocking of productivity enhancing management initiatives to unions' power at the workplace, a word on industrial relations seems apposite. Clearly, the decline of the industry has undermined the basis of workplace industrial relations: union density in textiles and clothing has fallen below 8 percent in 2011 (Carley 2013) and collective bargaining coverage was slightly above 13 percent compared to 23 in manufacturing. It would be implausible in this context to argue that productivity increases were hindered by collective labour. Equally implausible is the reverse argument, that productivity increases over 1999-2007 were due to the absence of unions as this argument is difficult to sustain after 2008.

[Table 2 about here] 
This article argues for an explanation that is embedded within the broader political economy. The industry has seen fundamental restructuring through competition from abroad, marked by falling clothing prices and the phasing out of the MFA, and resulting in a decline in the number of enterprises and employment twice as high during 1999-2006 (-8.1 and -16.2 percent, respectively) than for the whole period 1996-2014. In this context, high productivity growth was the result of the closure of less productive enterprises as well as significant work intensification in the face of massive job losses. The relatively high growth in real hourly pay has little to do with the power of collective labour; in fact, ASHE data show that it mirrors the growth rate of the national minimum wage (NMW) throughout.

Around 2007-08, however, a number of developments coincided, allowing the emergence of a different constellation in the UK. First, the CPI for clothing, still largely determined by factors in the global market, turned positive. Second, while qualitative wage differentials compared to SE Asia persist, they have narrowed: nominal gross monthly minimum wages have increased in Bangladesh, China, and India by 219,119 , and 74 percent, respectively, in the period 2006-2013, compared to 18 percent in the UK ${ }^{3}$. Third, this context allowed not only an increase in near-sourcing in major regional hubs but also their integration into fast fashion supply chains which is behind the renewed growth of apparel manufacturing in the East Midlands.

One key puzzle remains, however. How could such growth in apparel manufacturing be achieved when real pay grew at 5.2 percent per year and productivity growth was negative (2008-14)? Equally, while employment costs in UK wearing apparel grew twice as much as turnover and aGVA, employment costs do not even come to half the increase in turnover in the East Midlands (Table 1). Put differently, real employment costs in East Midlands wearing apparel have increased by 24.7 percent (2008-13) while real

\footnotetext{
${ }^{3}$ These data are taken from the ILOSTAT database, www.ilo.org/ilostat The reported wage differentials are significant even if inflation is taken into account: the CPI increased by 73, 26, 86 and 23 percent, respectively, in Bangladesh, China, India, and the UK over 2006-13 (IMF World Economic Outlook database, October 2015, http://www.imf.org/external/pubs/ft/weo/2015/02/weodata/download.aspx).
} 
median hourly pay has risen by 39.8 percent over the same period. The following sections discuss qualitative data on subcontracting, work and employment in the industry and analyse the puzzle as a function of the value chain and workplace relations engendered through fast fashion.

\section{Unauthorised Subcontracting to Escape Value Chain Pressures ${ }^{4}$}

The rise of fast fashion is significant in the effect it had on the governance of this particular strand of the value chain. Near-sourcing and the premium on quality and speed-to-market have led to a readjustment of the key parameters - time, price, and quality - as well as forms of coordination between lead firms, suppliers, manufacturers and, indeed, workers. Evidence from a range of UK highstreet fashion brands as well as suppliers and manufacturers from the East Midlands, the UK's largest sourcing hub, suggests that the particular form of governance is sustained through a very uneven distribution of costs and benefits across the value chain.

The headline attraction of near-sourcing is that the time span between placing an order and delivery to the store is reduced to under two weeks, compared to the 4-7 weeks manufacture and airfreight from the Far East would take (transportation on water alone would take 6 weeks). This means that the de facto competition of UK manufacturers is with Eastern Europe, parts of the Middle East and the North African rim: while transport from these regions would take between 2-7 days, the landed price between Turkey and the UK is, in fact, similar. Short lead times and quick turnaround allow lead firms to respond to short-term fashion trends and seasonal changes, reduce the need for extensive logistics and stocks, as well as the risk to be left with items that need to be sold at a discount. Lead firms clearly appreciated the flexibility close relationships could bring to the development process.

Near-sourcing brings ambiguities between pricing, costing and productivity into sharper focus. In principle, the profitability of fast fashion stems from the intensification of fashion seasons, innovative

\footnotetext{
${ }^{4}$ For the next two subsections see also Hammer et al (2015) which presents fieldwork data in more detail.
} 
and differentiated fashion, and the higher responsiveness to products that sell (and can therefore be reordered instantly). However, lead firms seem to benefit from this system more than manufacturers. A key factor here is how fast fashion structures competition amongst manufacturers. Respondents from all stakeholder groups, for example, have judged apparel manufacturing in Leicester as particularly price sensitive, resulting in the lowest factory gate prices buyers have encountered (across the UK).

Downward pressures on prices are built into the supply chain in two ways. First, near-sourcing framed pressures on time and price in different ways: on the one hand, a high volume/low margin strategy, on the other hand a low volume/high(er) margin strategy. Suppliers and manufacturers have spoken of the constant trade-offs they need to make between accepting large volumes at (sometimes) zero margin in order to make sure they can pay their overheads, and low volumes at high margins that allow them to make a profit. That low volume orders are often under 1,000 units and that manufacturers can only profit from trials once they are followed up by repeat orders (with no guarantees that the latter would go to the same manufacturer) only highlights the role of volatility on price levels. For example, only one lead firm was found to recognise the costs in developing and setting up small production runs by paying a premium for trials. The importance of continuous business relations was underlined by a supplier who developed and trialled 800 units of a garment, only for a follow-up order of 40,000 units to be given to a competitor. Second, the opacity of pricing practices is a reflection of the power dynamics in the supply chain: buyers tended to construct their costs top-down, deriving costs from their margin (around $60 \%$ in the UK), historical industry knowledge of what constitutes a 'going rate', as well as an assumption of productivity increases. While buyers rarely possessed knowledge of the price of input factors, manufacturers too rarely had a developed concept of costing. Crucially, labour costs were not specifically itemised and remained the classic residual and flexible element. It is not only margins, however, that are important in a context where a large number of small manufacturers constantly compete for a limited number of low volume orders: cash flow, throughput, 
and capacity are equally central. Again, lead firms' purchasing practices mirror the power relations in the value chain. For example, lead firms tend to pay suppliers within 60-90 days of delivery and it will take even longer for these payments to make their way to the manufacturer. If suppliers want to get paid sooner than the standard term they will have to accept a discount (in one best practice example, though, the lead firm settled its bills within 7 days which, in turn, allowed the supplier to pay the factory within the next fortnight). Equally, while lead firms appreciated the flexibilities close working relationships offered, practices such as last minute ordering, retrospective changes to orders already placed, lack of information on production plans, or cost price reductions for missing deadlines tended to be at the expense of manufacturers. This is even more significant given that manufacturers, in a 7 week production cycle, tend to deliver from week 3 onwards, thereby delivering benefits down the chain first while being the last to receive their share.

It might be assumed that more productive manufacturers would, over time, gain the upper hand in such an overly competitive market with very tight margins, forcing less productive factories out of the market. However, given the inherent volatility in the market and the need to fill order books, there is an incentive for suppliers and manufacturers to overstate their production capacity rather than to let go of orders from high-street retailers. Fieldwork has shown that unauthorised subcontracting (to second-tier factories) is a standard practice in the industry and occurs across well and less established firms. Unauthorised subcontracting, however, it is more than a response to order fluctuations. It goes far beyond the violation of a commercial contract and goes hand in hand with violations of a range of tax and work and employment regulations. It is based on dividing different groups of workers within as well as across firms: depending on their respective vulnerabilities, workers are subject to differences in pay rates, employment continuity, shift patterns, and working conditions. Unauthorised subcontracting, thus, constitutes a way to stabilise fluctuations in, both, orders as well as profits. The segmentation of manufacturers and workers constitutes a key feature in this respect. 


\section{Management-Labour Relations on the Low Road}

The power relations in the fast fashion value chain shift the manufacturers' focus primarily on workplace social relations, rather than strategy and operations where discretion is much more limited. This reinforces sociological arguments from the productivity debate (e.g. Nolan and O'Donnell 1995) that emphasise the management of the labour process, the organisation of work, as well as the employment relationship. As lead firms incorporated fast fashion into their business model, the ensuing supply chain practices pushed manufacturers' business model closer to the blurred boundary between the formal and informal economy. This concerned, both, firms' informal (unauthorised) subcontracting arrangements as discussed above, as well as their employment practices.

Trends from ASHE data give an indication of the adverse impact of value chain restructuring on pay, particularly during the boom period. For example, real median gross hourly pay in UK apparel manufacturing grew considerably slower than the NMW (in 2015 prices), and the gap between male and female hourly pay increased from an average of 19.6 (1999-07) to 23.4 percent (2008-14). ASHE data also point to very unfavourable developments for female workers in the East Midlands: while the real NMW and male median pay grew by 154 and 161 percent (1998-2015), respectively, female median pay rose by a mere 102 percent. The level as well as growth rate of the lowest decile of pay coincided virtually throughout with the NMW. This situation of very low wages, however, takes on yet another dimension in the light of the qualitative data of the research.

All qualitative data in this study pointed to an industry norm of $£ 3$ per hour which stood in sharp contrast to the then NMW rate of $£ 6.50$ per hour. This was respondents' account of the average 'going rate': senior (and often very skilled) supervisors or cut-make-and-trim (CMT) workers could earn the NMW whereas packers' rates could be as low as $£ 1$ per hour. Overall, unpaid wages constituted a significant part of the industry: assuming an average wage of $£ 3$ per hour for 75 percent of the 13,200 
workers (though some respondents spoke of 90 percent) and a 28 hour working week in apparel manufacturing in the East Midlands the defrauded weekly wages in the region would come to $£ 970,000$. Over the course of a whole year this would add up to $f 50$ million or 20 percent of the regional industry's approximate gross value added.

As important as the actual wage rate was the mechanism of wage formation which, except for the issuing of a pay slip, was entirely informal. Interestingly, workers reported a 'going rate' of $£ 3$ per hour despite the contrast with actual practice: workers tended to be employed, without written contracts, at NMW rates for a particular number of hours, very often 16-20 hours per week, for which a pay slip was issued and wages were paid cash-in-hand. In fact, the survey revealed considerably longer average working times of 28 hours per week. However, due to the sample as well as respondents' reticence to disclose inconsistencies in their wage and benefits histories, this figure might underestimate actual working hours. Beyond the wages paid on the basis of the wage slip, workers were often asked by their employers to 'make up' income for their remaining working hours through welfare benefits, notably working tax credits, child tax credits, and housing benefits. Indeed, 50\% of the survey respondents reported receiving one or more of those benefits.

An assessment of these data needs to consider employer views that such 'composite wages' were at the request of workers, and that flexibility in recording working time and pay allowed employers to recruit more experienced and skilled workers. The fact that workers received benefits as indicated by the survey does not automatically mean that they were complicit in under-recording working time and pay. However, a consideration of relative benefits and power asymmetries in this particular employment relationship speak against composite wages arising due to worker-demand. Community organisations, virtually the only instance workers turned to with work-related issues, reported that problems were exclusively framed in terms of household debt, particularly of arrears with rent, Council Tax, or utility bills. In the context of an average monthly wage of $£ 584$ and a weekly household income of $£ 229$, it 
seems more plausible that debt problems arise because of low wages rather than in spite of workers' ability to dictate 'composite wages' to their employers. Rather, 'composite wages' benefit employers as they reduce their tax liabilities on wages and firm-level benefits and as the 'construction' of welfare benefits as a wage components effectively subsidises their wage bill.

This picture on pay was compounded by work and employment conditions that exploited the vulnerabilities of different groups of workers. Respondents tended to consider their job 'as and when required', regardless of their formal status: while 17 respondents (out of 30) considered their job as permanent, two thirds stated that they did not work the same number of hours every day, the same number of days every week or the same number of hours every week. Employment directly responded to the order book at a given point in time: in fact, 60 percent of respondents reported that they were home 3-4 times per month due to lack or fluctuation of orders. Pay levels and working conditions differed between the overwhelmingly female workforce of SE Asian background (who often hold UK citizenship but whose limited language skills tend to prevent them from finding employment elsewhere), migrants on student or visitor visas, as well as undocumented migrants. Furthermore, health problems, inadequate health and safety standards, verbal abuse, bullying, threats and humiliation, lack of toilet breaks are unevenly distributed across this rough segmentation of the workforce. Such conditions resulted in very high rates of turnover: between half and two thirds of the survey respondents changed jobs over the last year and, when asked about turnover at their workplace, more than one third reported turnover rates of more than 50 percent, in two cases reaching above 100 percent.

Survey data suggest a straightforward link between industrial relations, work and employment conditions, and productivity. The lack of organised voice at the workplace meant that workers were not informed of their employment rights and only had their fellow workers to turn to for advice; only a small minority consulted the Citizen Advice Bureau or their community organisations. Mirroring this lack of 
voice, the overwhelming majority of survey respondents stated that they are not consulted about changes to their job or work organisation. This underlines the paradox that the role of work organisation and productivity was very much accepted by key industry stakeholders (Miller 2013), yet dialogue over factory productivity, pricing and labour costing was wholly dependent on actors outside the workplace. Thus, actors further down the supply chain not only shaped a large part of the standards under which garments were produced; they also largely monitored those standards on behalf of workers.

\section{Conclusion}

The above case of near-sourcing has shown that the apparent tension in UK apparel manufacturing between low producer prices, low productivity, and high wage growth was resolved through a shift to the informal economy in order to enable high growth. The focus on fast fashion in the GVC tradition emphasised the changing power relations in the value chain, expressed through tight purchasing practices, product and process standards, that is, requirements regarding price, quality, and speed. However, during the years of downturn and the beginning of the boom, the industry has largely failed to invest in its technological capabilities and to shift towards higher value-added production. In consequence, the management of labour became the main way to absorb the above tensions. It was argued that the conditions of near-sourcing apparel from the UK can only be analysed through a focus on the social relations at work - in the context of embedded regimes of competition and industrial relations. In line with industrial districts and value chain literatures, different forms of inter-firm relations do matter. Going beyond these literatures, however, the above case also underlines the role of factory regimes that determine key parameters such as productivity and thereby constitute a necessary condition for specific types of inter-firm relations.

A broader political economy perspective on apparel value chains - integrating how lean retailing, purchasing and supply chain management practices mediate power relations across the functional 
division of labour, a captive female workforce, and enforcement regimes unfit to regulate changing and segmented product and labour markets - is far from trivial. In fact, the remarkable growth in UK apparel manufacturing is based on the tensions between quality and supply chain improvements, and the reduction of labour costs (Prime Minister's Office 2014) - contradictory conditions that threaten the very sustainability of the industry. From a policy perspective, raising firm capabilities might well be important but by itself unlikely to achieve industrial upgrading. Rather, capabilities are embedded in a broader political economy and can be achieved through different routes: through drawing on different segments of the labour force or different forms of production and labour workforce management which, in turn, expose firms to product and labour market competition in different ways. Does near-sourcing apparel have any future, then, given the central role of informal subcontracting networks and informal employment? After all, the foregoing evidence could be seen as proof that labour costs do trump the gains that could be achieved from speed-to-market advantages.

The answer put forward here is that there clearly is potential in near-sourcing apparel, its sustainability, however, needs to be assessed in the context of a range of institutions at macro and micro level. First, the division of power within the value chain clearly shapes key outcomes as it impacts on the direct costs and benefits between lead firms, suppliers and manufacturers and, furthermore, concentrates the latter's leverage on intensifying work as opposed to increasing productivity. Second, in conjunction with the fragmentation of supply chains, the enforcement of work and employment regulations has been reduced considerably over the last decades and to a large extent left to private actors. However, while a range of private monitors and auditors can be made out in factories, this tends to leave out the representation of worker interests as monitoring is, at best, on behalf of workers. Finally, the impact value chain restructuring had on a few regional economies in the UK suggests that a minimum involvement of the state, for example in setting the NMW, might in fact exacerbate market problems in the form of growing asymmetries in the functional division of labour (recent debates on agricultural and 
food value chains seem to confirm this). Preventing the adverse integration of workers requires a greater role for currently marginalised actors such as collective labour and the state. In fact, historical precedents do exist: Anner et al (2014), for example, have discussed industry agreements within apparel manufacturing that largely succeeded in regulating the apparel value chain. While the precise historical context has, of course changed since, these agreements constitute an important reference point for the social regulation of apparel value chains.

\section{References}

Anner, M., Bair, J., and Blasi, J (2014) Toward joint liability in global supply chains: Addressing the root causes of labor violations in international subcontracting networks, Comparative Labor Law and Policy Journal, 35(1), 1-43

Bailey, D. and L. DePropris (2014) Manufacturing reshoring and its limits: the UK automotive case, Cambridge Journal of Regions, Economy and Society, 7(3), 379-395

Bair, J. (2009) Global commodity chains. Genealogy and review, 1-34, in J. Bair (ed.), Frontiers of Commodity Chain Research (Stanford, CA: Stanford University Press)

Carley, Mark (2013) UK: The representativeness of trade unions and employer associations in the textile and clothing sector, http://eurofound.europa.eu/observatories/eurwork/comparativeinformation/national-contributions/united-kingdom/uk-the-representativeness-of-trade-unions-andemployer-associations-in-the-textile-and-clothing

Doeringer, P. and S. Crean (2006) Can fast fashion save the US apparel industry?, Socio-Economic Review $4(3), 353-377$

Edwards, P. (2005) The challenging but promising future of industrial relations: Developing theory and method in context-sensitive research, Industrial Relations Journal 36(4), 264-282

Fine, B. (1998) Labour market theory. A constructive reassessment (Abingdon: Routledge)

Gereffi, G., J. Humphrey and T. Sturgeon (2005) The governance of global value chains, Review of International Political Economy 12(1), 78-104

Gibbon, P. (2001) At the Cutting Edge: UK Clothing Retailers and Global Sourcing. CDR Working Paper 01.4 (Copenhagen: Centre for Development Research)

Gibbon, P., J. Bair and S. Ponte (2008) Governing global value chains: an introduction, Economy and Society 37(3): 315-38. 
Gray, J.V., Skowronski, K., Esenduran, G. and M.J. Rungtusanatham (2013) The Reshoring Phenomenon: What Supply Chain Academics Ought to Know and Should Do, Journal of Supply Chain Management, 49(2), 27-33

Grimshaw, D. and J. Rubery (2005) Inter-capital relations and the network organisation: Redefining the work and employment nexus, Cambridge Journal of Economics 29(6), 1027-1051

Hammer, N. and Riisgaard, L. (2015) Labour and segmentation in value chains, 83-99, Newsome, K., Taylor, P., Bair, J. and Rainnie, A. (eds.), Putting labour in its place. Labour process analysis and global value chains (London: Palgrave).

Hammer, N., Plugor, R. Nolan, P. and Clark, I. (2015) A New Industry on a Skewed Playing Field: Supply Chain Relations and Working Conditions in UK Garment Manufacturing (Leicester, London: University of Leicester/CSWEF, Ethical Trading Initiative).

HC Deb 18 March 2015, vol. 594, col 758, http://www.publications.parliament.uk/pa/cm201415/cmhansrd/cm150318/debindx/150318-x.htm

Lan, T. (2015) Industrial District and the Multiplication of Labour: The Chinese Apparel Industry in Prato, Italy, Antipode 47(1), 158-178

Lane, C. and Probert, J. (2009) National capitalisms, global production networks. Fashioning the value chain in the UK, USA, and Germany (Oxford: OUP)

Long, K. (2010) Labour productivity measure from the ABI: 1998-2007, Economic and Labour Market Review 4(5), 30-43

Miller, D. (2013) Towards sustainable labour costing in UK fashion retail, Capturing the Gains Working Paper 14 (Manchester: University of Manchester)

Morse, J (2010) Procedures and practice of mixed methods design. Maintaining control, rigor and complexity, 339-352, in Takkashori, A. and C.Teddlie (eds) SAGE Handbook of Mixed Methods in Social and Behavioural Research (London: Sage)

Newsome, K., Taylor, P. Bair, J. and A. Rainnie (eds) (2015) Putting Labour in Its Place. Labour Process Analysis and Global Value Chains (London: Palgrave)

Nolan, P. and K. O'Donnell (1995) Industrial relations and productivity, 397-433, Edwards, P (ed.) Industrial relations. Theory and practice (Oxford: Blackwell)

Prime Minister's Office (2014) Businesses Are Coming Back, https://www.gov.uk/government/publications/businesses-are-coming-back/businesses-are-comingback

Riddle, E., D. Bradbard, J. Thomas and C. Kincade (1999) The role of electronic data interchange in quick response, Journal of Fashion Marketing and Management 3, 133-147 
Taplin, I.M. (2014) Global Commodity Chains and Fast Fashion: How the Apparel Industry Continues to Re-Invent Itself, Competition and Change, 18(3), 246-64

Walsh, J. (1991) The performance of UK textiles and clothing: recent controversies and evidence, International Review of Applied Economics 5(3), 277-309 
Table 1: Manufacture of Wearing Apparel in the East Midlands and the UK (percentage changes)

\begin{tabular}{|l|c|c|c|c|}
\hline & \multicolumn{2}{|c|}{ UK } & \multicolumn{2}{c|}{ East Midlands } \\
\hline & $\mathbf{1 9 9 8 - 2 0 0 7}$ & $\mathbf{2 0 0 8 - 2 0 1 4}$ & $\mathbf{1 9 9 8 - 2 0 0 7}$ & $\mathbf{2 0 0 8 - 2 0 1 3}$ \\
\hline Real Turnover & -55.8 & 11.1 & -56.9 & 52.4 \\
\hline Real aGVA & -58.8 & 10.4 & -63.8 & 39.3 \\
\hline Real Employment Costs & -66.5 & 22.4 & -60.3 & 24.7 \\
\hline & & & & -7.1 \\
\hline $\begin{array}{l}\text { Local Units in VAT/PAYE Based } \\
\text { Enterprises }\end{array}$ & -57.4 & -8.3 & -52.5 & 0.0 \\
\hline Employment (1) & -76.3 & 16.7 & -76.5 & \\
\hline
\end{tabular}

Source: ONS, Annual Business Survey (ABS), ABS Regional Statistics, deflated by PPI Wearing Apparel or CPI All Items. Data for employment are taken from the Annual Survey of Hours and Earnings (ASHE) and are indicative only! They do, however, offer a rough picture of regional employment trends.

(1) Most recent ASHE data indicate that employment in East Midlands apparel manufacturing increased from 4,000 to 7,000 over the years 2013-2015, amounting to a 75 percent rise. By contrast, the Business Register Employment Survey records a rise from 8,700 to 13,200 employees, incl. working proprietors (2008-10).

Table 2: Average Growth Rates of Labour Productivity and Pay in UK Manufacturing and Wearing Apparel

\begin{tabular}{|l|c|c|c|c|}
\hline & \multicolumn{2}{|c|}{ Manufacturing } & \multicolumn{2}{c|}{ Wearing Apparel } \\
\hline & $\mathbf{1 9 9 9 - 2 0 0 7}$ & $\mathbf{2 0 0 8 - 2 0 1 4}$ & $\mathbf{1 9 9 9 - 2 0 0 7}$ & $\mathbf{2 0 0 8 - 2 0 1 4}$ \\
\hline PPI & 1.74 & 2.87 & -0.03 & 1.63 \\
\hline Total Net Capital Expenditure & -3.66 & 9.82 & -4.08 & 35.99 \\
\hline Labour Productivity & 6.66 & 6.37 & 9.30 & -0.19 \\
\hline Real Pay/Hour & 5.29 & 5.02 & 6.35 & 5.10 \\
\hline
\end{tabular}

Source: ONS. Data for labour productivity are taken from ABS for consistency (Long 2010) and calculated as real aGVA/total median hours worked. Data for labour productivity can fluctuate significantly but the data and division into two phases is consistent with other ONS productivity measures. 
Figure 1: PPI and CPI Growth Rates in the UK, 1997-2015

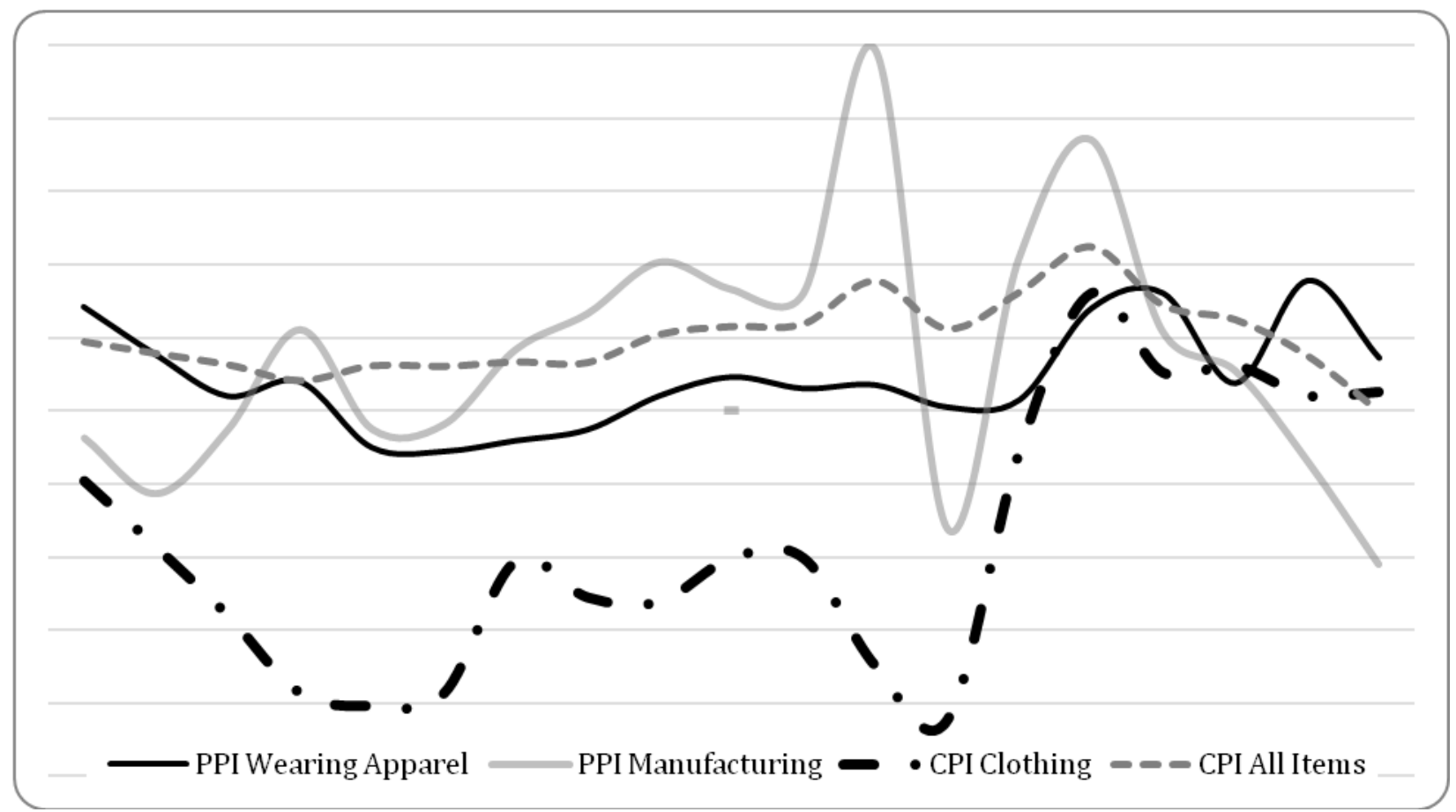

Source: ONS; PPI data are from table MM22 (K37S; K36V), CPI data from table MM23 (D7BT; D7CC). 